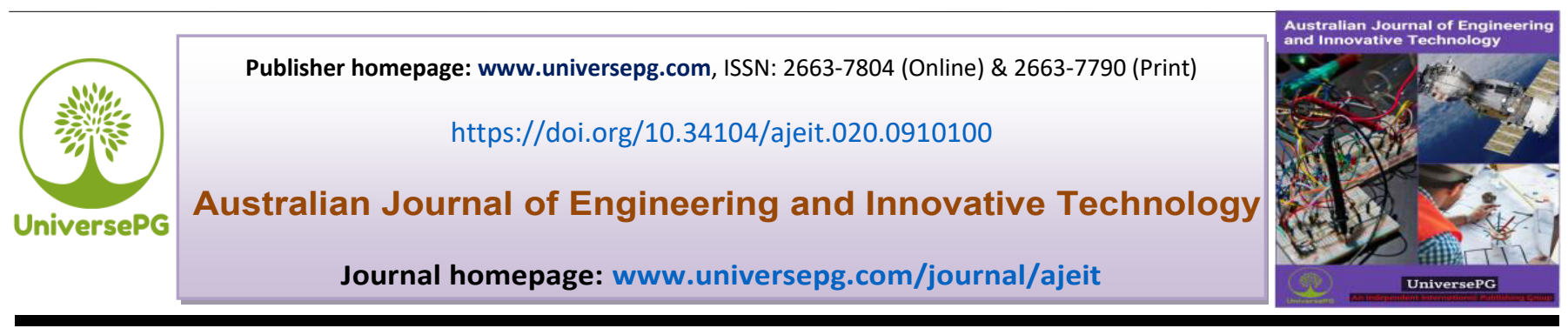

\title{
Assessment and Evaluation of the Production Merchandising of a Denim Pant
}

\author{
Faruq Hosen $^{1 *}$, Muhammad Mamun Hossain ${ }^{1}$, Sayed AKM Jahidul Hassan ${ }^{1}$, Mahadee Hassan ${ }^{1}$, Arafat \\ Alam $^{1}$, and Kamruzzaman Bisal ${ }^{1}$ \\ ${ }^{1}$ Department of Textile Engineering, Sonargaon University, Dhaka, Bangladesh. \\ *Correspondence: texfaruq@gmail.com (Faruq Hosen, Lecturer, Department of Textile Engineering, Sonargaon University, \\ Dhaka, Bangladesh).
}

\begin{abstract}
This study was designed to investigate the production merchandising of a denim pant. Denim pants are a significant prospect for the RMG sector in Bangladesh with a huge future. Without a doubt pricing is the key important factor in the global competitive market. It is difficult to stay in the clothing market without spending the minimum on clothing. The research centre on the whole factor which is directly involved to the FOB cost of basic denim pants where it includes textile cost, labor cost, and accessories cost, savings, charge making cost, washing and packing cost which are shown chronologically. With the aim that the total price spans can be contained as well as demonstrating sum FOB cost. Merchandising means buying, producing, and selling any goods or products, or services for the local or international market. All activities related to the export purchase collection of any garment of a certain design for a certain quantity, production of garment with precise attention to the garment level required for garment analysis, production of that quantity of garment required, and production timetable and exporting the samples within the fixed time frame, may be called apparel merchandising. In production merchandising, a production merchandiser executed production-related all activities in the garments factory. In this study, basic 5 pocket denim pant (ladies) is used and the total order size was 23920pcs. The importer and Country name was Pizzaitalia-Italy.
\end{abstract}

Keywords: Ladies denim pant, Consumption, Costing, Merchandising, Evaluation, and Woven garments.

\section{INTRODUCTION:}

It is pointless to say that without denim; fashion is incomplete. No other textile has been as widely accepted as product in the history of fabrics and it is the material of generations, used by person of all levels and ages (Kumari \& Khurana, 2016; Du et al., 2019). The newly developed denim of various designs enriched with softness, lightness and comfortable attributes have added a new dimension to the world of fashion in all seasons (Wang et al., 2019). Comfort properties in clothing are considered as one of the essential quality criteria for consumers. Therefore, it is required to take into account the features of comfort in textiles (Rahman et al., 2019). Basically, the costing data made of fabric cost, accessory cost, CM cost and another costs. All of these costs are behind for the end price of a good. To build a full dress, lots of chains have to be maintained. As the distribute chain of the RMG factory is quite divers, each part of the chain supports towards the end cost of the industry (Karim et al., 2019). 
The easy distribute chain in the factory started making fiber production, in the case of manufactured fiber and goes on various processes such as yarn production, weaving, dyeing, finishing, and printing, sewing, cutting, sewing, packaging and much more. Each component is directly or indirectly attached in the cost, which continues to be the costume. The interdependence of cost in the present example is a change of production line without cost which means that a machine has to re-toll whenever the production process alters from one sample to another. The denim product discipline offers many more definitive and informative promises of the contemporary political economy and the interplay between production and use. This study has completed an overview of the strategies currently spent in the RMG industry. Expenses include all activities such as fiber purchase, weaving, dyeing, fabrication cost, cost of all materials, main cost, printing, embroidery, wash, carton casting, poly cost, test, inspection, delivery, commercial, and shipment cost. The manufacturers are using various techniques to make cost adopts. Although in this modern period, manufacturer used numerous modern software and techniques to make cost sheet. The cost of clothing is defined to determine the price that the retailer and the buyer have to pay for the products. The analysis was developed the background of costing and unworn system of production cost from manufacturing of fabric to wholesaler and to consumer (Mohibullah et al., 2019).

The yield cost of a good is not always the similar as it was estimated at the sample range. Different factors can affect the yield cost of a good which is forceful in nature. These dynamic parameters can affects cost of preparing on a tiny day which can build a key impact on daily production and price of the good. Most people in the garment factory feel that it is important to change the garment price analysis, especially for finished products (Gandh et al., 2019).

Expenses can be borne at the initial step of production or at different stages of pre-financing. This is done during good development before sampling. Final prices that are incurred prior to production and pricing are respent, where there is a change in equipment, manufacturing process, components or clothing items and actual prices are examined during production UniversePG I www.universepg.com
(Choudhary, 2015). Basically, to produce denim pants, you need some trim and accessories according to the design or needs of the consumers. Designers examine required textile with trims, and accessories and related all elements according to design (Camargo et al., 2003).

Merchandiser is the interface of buyer and exporter. $\mathrm{He}$ is relating for shipments from order analysis. Thus, merchandising is an extremely valuable segment of the clothing industry. Merchandising is the department that mediates the marketing and manufacturing departments. Sometimes, the merchandising department has to pay the price and the price as well. In any case, a merchandiser is a person whose duty is to execute orders accurately according to price and price. So this is a more valuable category. It can be clearly assumed that the purchase of garments export which is L / C exported, the yield of those samples based on the satisfaction of the importer within a limited period of time is not so easy. The activities involved in the RMG business are usually performed by a dynamic and expert person known as a garment trader.

The "garment merchandiser" is one of the key players in the RMG manufacturing and garment export sector. The merchandisers in Garment industries observe the sample given by the consumer and execute the work in the organizations such as depending upon the range of the order the garment merchandisers co-ordination the origins of production, raw material, yarn fabric, fabric conditions and quality methods. In garment industries the merchandiser is the people who integrate the assessment of raw good, fabric production and formal apparel production. The merchandisers face the continuous change of style and its trends necessitated garment merchandisers in the level playing field. Professional qualities of a merchandiser are computer skills, good communication skills written and oral, should have knowledge of mathematics, always be bold and active, knowledge of different fabrics, knowledge about garment manufacturing, knowledge on washing, know banking, delivery, commercial, shipping, Need to have at minimum one related training, other key qualities are able to take high stress, and must take responsibility for taking responsibility. Merchandising is the area that mediates the marketing and manufacturing divisions. It is the method, practice, and 
operation used to enhance and maintain certain types of commercial work. This includes looking at the development and management of product lines from start to finish.

Marketing and Merchandising Division - A body of traders and marketers work together under the head of profit control. Merchandisers handle foreign buyers. The groups are built based on the consumers being handled. Merchandiser is the bridge between the industry and the buyer. He has to look after any job such as cutting products, making clothes, finishing clothes, documenting, finally buying the raw goods needed for shipping. He is the people responsible for making the product. The sample Export area usually has many sections like Store, Cutting, Manufacturing, Packing, Checking, etc. The Mark-Handsizing section is a connecting device for all. The work of a merchandiser is to dealing with customers as well as the total section in the room. The merchandiser is a person who builds a product relationship between an exporter and a buyer. Working Procedure of a Production Merchandiser in Woven Garments Industry: The main working procedures of a woven garments merchandiser are discussed in the below:

\section{Fabrics follow up}

The first and most important one is "Fabrics follow up" and the second one is "Order implementation". Among two key points, now I will state about the first key important option named "Textile follow up".

\section{Textile follow up holds the following issues -}

- Fabric booking and order,

- Fabric in-housed,

- Local trims booking,

- Accessories development and approval.

All the main five key parameters for the "Textile follow-up" are stated in the below:

Fabric booking and Order - When the consumers sends his easy with all the details instructions, a knitted garments merchandiser should be requested following the buyer's instructions regarding the types of textile such as cotton denim, spandex denim, slab denim, 2/1 RHT etc. and depend on the order quantity.

Fabric in housed - After finishing the fabric booking, a knitted garments merchandiser should sort the correct UniversePG I www.universepg.com fabric as per the consumers' instructions and also sort them before printing, packing, and embroidery approval (if there is any printing, packing, and embroidery instruction).

Local trims booking - By completing the above two stages, the merchandiser should create sure to stay at home before booking local accessories like local sewing threads, zippers, buttons, metal rivets, etc. and starting the sewing approach.

Accessories Development - As stated to the order specification, if any accessory development such as logo button, logo rivet, logo zipper driver, all kinds of labels etc. is required, it should be developed on an urgent basis.

Accessories Approval - These should be delivered to the buyer for approval after the accessories have been developed. When the merchandiser has approved these accessories, he should handle the necessary amount of accessories before starting the sewing process. One thing to note here is that if you are not able to handle all the local accessories before sewing, you will not be able to remote the following methods in your own way. This is a more important piece of advice for a goods merchandiser.

Order execution - The second important factor in sending a consignment on time is order execution. The order execution has the following properties:

- Pattern making,

- Fit sample producing,

- Wash development,

- Wash approval and Comments,

- P.P sample producing,

- Cutting the textile and Sewing,

- Complete the washing method,

- Finishing and Quality Control review.

This analysis was created to focus the overall pricing process of denim pants. While spending these things are gradually falling fabric price, trims and accessseries price, washing price, making price, poly and cartooning price and then the end FOB price. The ratio of the order also affects the end price; this price of fabric and sewing fiber also adds a significant element that is represented very carefully. Market order \& overall circumstance of manufacturer country are considering during pricing. 


\section{MATERIALS AND METHODS:}

\subsection{Materials}

Fabric - In this study work, $98 \%$ of cotton $2 \%$ of elastane denim Scuro colored fabrics was used. The textile GSM (grams per square meter) was 325 (after wash), 3/1 right hand twill fabric width 57 inch.

\section{Product Sketch}

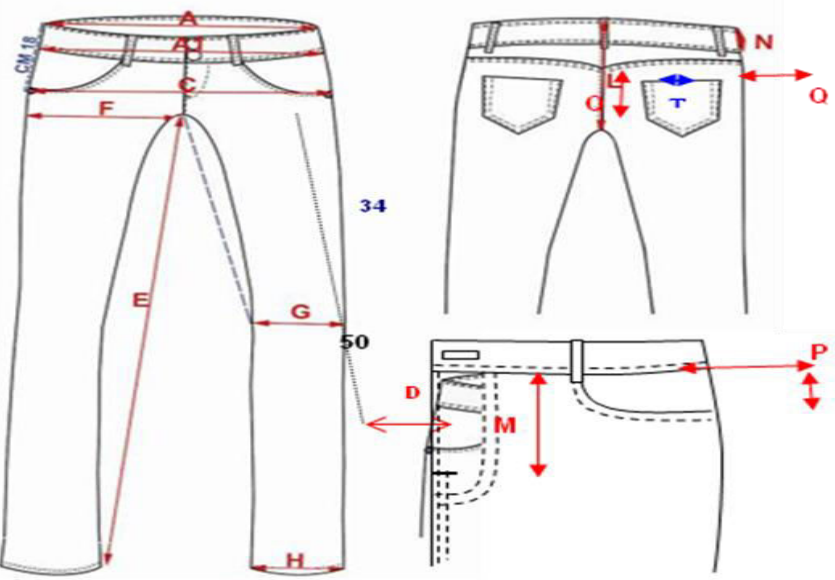

Fig 1: Style: Basic 5 Pocket Denim Pant (Ladies) Buyer name and Country: Pizzaitalia (Italy),

Total Order Quantity: 23920 pcs.

\section{Size Wise Order Quantity Chart:}

$\begin{array}{llllll}\text { Color } & \mathbf{4 0} & \mathbf{4 2} & \mathbf{4 4} & \mathbf{4 6} & \mathbf{4 8} \\ \text { Denim Scuro } & 2990 & 4198 & 4198 & 3307 & 1208 \\ \text { Denim } & 1894 & 2005 & 2005 & 1114 & 1001\end{array}$

\section{Color Wise Order Quantity Chart:}

$\begin{array}{ll}\text { Color } & \text { Quantity } \\ \text { Denim Scuro } & 15901 \\ \text { Denim } & 8019\end{array}$

Table 1: Sample Specification Sheet

\begin{tabular}{|c|c|c|c|c|c|c|}
\hline \multicolumn{2}{|c|}{$\begin{array}{c}\text { Measurement } \\
\text { After Treatment } \\
\text { In CMS }\end{array}$} & \multirow{2}{*}{$\begin{array}{l}40 \\
34\end{array}$} & \multirow{2}{*}{42} & \multirow{2}{*}{$\begin{array}{l}44 \\
38\end{array}$} & \multirow{2}{*}{$\begin{array}{l}46 \\
40\end{array}$} & \multirow{2}{*}{$\begin{array}{l}48 \\
42\end{array}$} \\
\hline A & $\begin{array}{l}1 / 2 \text { waist }+ \\
\text { elastic }\end{array}$ & & & & & \\
\hline $\begin{array}{l}\text { A } \\
1\end{array}$ & $\begin{array}{l}1 / 2 \text { waist from } \\
\mathrm{cm} 4 \\
\text { relax/stretchin } \\
\mathrm{g}\end{array}$ & 35 & $\begin{array}{c}37 / 4 \\
8\end{array}$ & $\begin{array}{c}39 / 5 \\
0\end{array}$ & $\begin{array}{c}41 / 5 \\
2\end{array}$ & $\begin{array}{c}43,5 / 54 \\
5\end{array}$ \\
\hline B & $\begin{array}{l}1 / 2 \text { hip from } \\
\mathrm{cm} 12 \\
\text { including } \\
\text { waist }\end{array}$ & 36 & 38 & 40 & 42 & 44,5 \\
\hline C & $\begin{array}{l}1 / 2 \text { hip from } \\
\mathrm{cm} 18\end{array}$ & 38 & 40 & 42 & 44 & 46,5 \\
\hline
\end{tabular}

\begin{tabular}{|c|c|c|c|c|c|c|}
\hline & $\begin{array}{l}\text { including } \\
\text { waist }\end{array}$ & & & & & \\
\hline $\mathbf{E}$ & inseam lenght & \multicolumn{2}{|c|}{72} & \multicolumn{2}{|c|}{73} & \\
\hline $\mathbf{F}$ & $1 / 2$ thigh & 22 & 23 & 24 & 25 & 26,5 \\
\hline $\mathbf{G}$ & $\begin{array}{l}1 / 2 \text { knee from } \\
\mathrm{cm} 33 \text { rise }\end{array}$ & $\begin{array}{c}15, \\
2\end{array}$ & 16 & 16,8 & 17,6 & 18,6 \\
\hline $\mathbf{S}$ & $\begin{array}{l}\text { calf from cm } \\
50 \text { rise }\end{array}$ & $\begin{array}{c}14, \\
2\end{array}$ & 15 & 15,8 & 16,6 & 17,6 \\
\hline H & $1 / 2$ bottom & $\begin{array}{c}11 \\
5\end{array}$ & 12 & 12,5 & 13 & 13,7 \\
\hline I & $\begin{array}{l}\text { front rise } \\
\text { including } \mathrm{w} / \mathrm{b}\end{array}$ & 19 & 20 & 21 & 22 & 25 \\
\hline $\mathbf{L}$ & $\begin{array}{l}\text { back rise } \\
\text { including } \mathrm{w} / \mathrm{b}\end{array}$ & 33 & 34 & 35 & 36 & 39 \\
\hline M & $\begin{array}{l}\text { fly length } \\
\text { from bartak }\end{array}$ & \multicolumn{2}{|c|}{9} & \multicolumn{2}{|c|}{10} & \\
\hline $\mathbf{N}$ & $\begin{array}{l}\text { waist band } \\
\text { height }\end{array}$ & & & & & \\
\hline $\mathbf{P}$ & $\begin{array}{c}\text { front pocket } \\
\text { opening/depth }\end{array}$ & \multicolumn{2}{|c|}{$9 / 6$} & \multicolumn{3}{|c|}{$9,5 / 6,5$} \\
\hline $\mathbf{Q}$ & $\begin{array}{l}\text { back pocket } \\
\text { opening/depth }\end{array}$ & \multicolumn{2}{|c|}{$13,5 / 14,5$} & \multicolumn{3}{|c|}{$14 / 15$} \\
\hline $\mathbf{R}$ & $\begin{array}{l}\text { belt loop } \\
\text { length/width }\end{array}$ & & & & & \\
\hline $\mathbf{T}$ & $\begin{array}{l}\text { Back Pocket } \\
\text { Position }\end{array}$ & \multicolumn{2}{|c|}{3} & \multicolumn{3}{|c|}{3,5} \\
\hline
\end{tabular}

Fabric Consumption: 14 yards per Dzn. By Size Specification.

Fabric pricing- $\$ 46,380.88$

Trims, Accessories Costing: $\$ 8030.28$

Table 2: List of Trims, Accessories and Costing

\begin{tabular}{|l|l|l|}
\hline Accessories & 01 & Sewing Thread \\
\hline & 02 & External Label \\
\hline & 03 & Button \\
\hline & 04 & Zipper (Zt0055) \\
\hline & 05 & Main Label \\
\hline & 06 & Elastic \\
\hline & 07 & Hangtag \\
\hline & 08 & Barcode (H0102 \\
\hline & 09 & Care Label \\
\hline & 10 & Metal Plate \\
\hline & 11 & Polybag \\
\hline & 12 & Blister Poly \\
\hline & 13 & Carton \\
\hline & 14 & Security Tag \\
\hline & 15 & Excess \\
\hline
\end{tabular}


CM Price: \$38.37/DZN

FOB Price: \$6.20-Unit Price / Set.

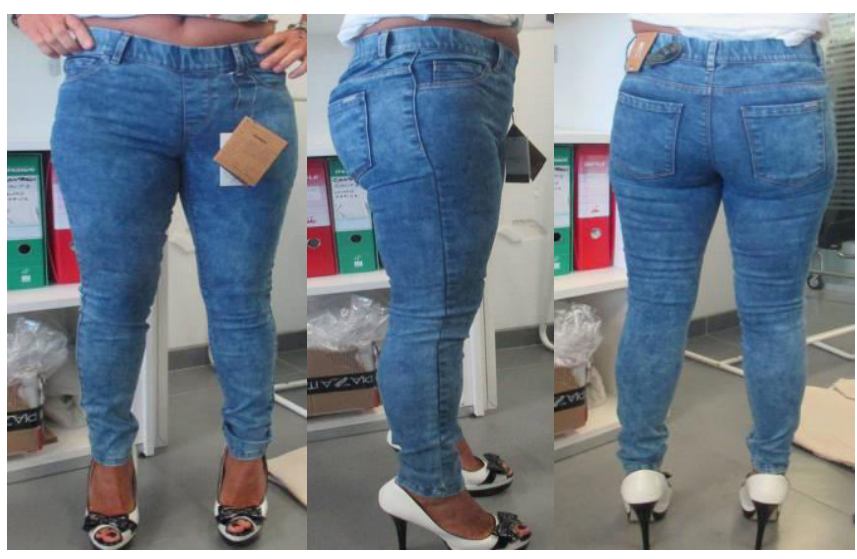

Fig 2: Shipment Fit Sample.

\subsection{Methodology}

\subsubsection{Working Plan of Production Merchandising}

Order gained from the consumer with details

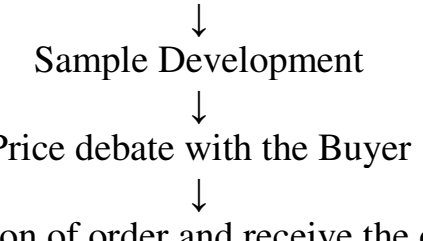

Authentication of order and receive the order sheet

Make consumer requirement good (Fit, Proto, etc) for approval

$$
\downarrow
$$

Make order for raw fabric

Make order for trims and accessories

Swatch board creating and approval

Raw good collection and also take it in factory

Review and also listing for focus

Create P.P (pre production garment) with all real

Pre-production meeting of the sample

Initiate bulk production

Store daily production and QC data

$$
\downarrow
$$

Yield online review by strong quality body

Sample delivered to third party testing Lab
Create last inspection for bulk production

Shipment of the final sample

Handover all data to the Buyer

Take payment currency from the Bank

\subsubsection{Woven Samples Production Process}

\author{
Design / Sketch \\ $\downarrow$ \\ Pattern Design
}

Sample Making

Production Pattern

$\downarrow$

Grading

$\downarrow$
Marker Creating

Spreading

$\downarrow$

Cutting

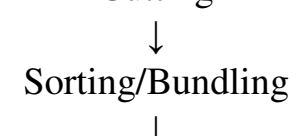

Sewing/Assembling

Inspection

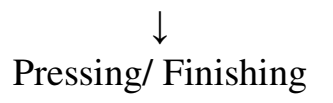

Final Inspection

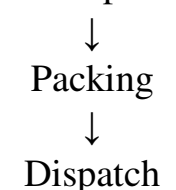

2.2.3 Garments Sample - Sample is the proto type or model of the sample. It is a model of what the bulk production is going to be done. Making a sample is an essential first step for each item. Also making garment samples is one of the key important methods in RMG factory as it will enable the buyer to create attraction towards the industry.

\subsubsection{Types of Sample}

\section{A. Development samples}

- Proto sample/Design sample 
- Fit sample

- Photo shoot sample

- Mock up sample

- Sort set sample

- Salesman sample (SMS)

- Approval sample

- Pre-production sample (PPS)

\section{B. Production samples}

- Top over production garment / internet sample

- Shipment sample.

\subsubsection{Various Steps of Garment Sample Preparation}

Samples Design or Sketch preparation

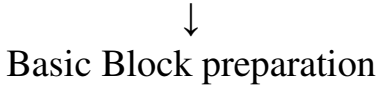

Working Pattern design

Textile cutting<smiles>[AlH2]</smiles>

Print/Embroidery design (If required)

$\downarrow$

Sewing of the sample

$\downarrow$

Finishing of the garments

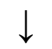

Sample Garments design

$\downarrow$

Evaluation of Problem of Sample or Related Matter

Costing

$\downarrow$

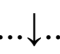
Handover

\section{to Buyer \\ Approval of Sample \\ $\downarrow$ \\ Preparation of Production design}

2.2.6 Duties of a Production Merchandiser - Product development, market and product analysis, sales of ideas, booking orders, delivery confirmation, designing and sampling, expenditure, raw materials, flow monitoring, production follow-up compromises, follow-up payments, and internal and external communication-registration.

2.2.7 Fabric Expenditure and Pricing - Fabric Expenditure is the term which is related with the garments costing. Fabric consumption is relating on the range of UniversePG I www.universepg.com the samples and is to search the textile consumption as per the buyers specification sheet or measurement chart.

2.2.8 Samples Production Process - As a garment maker, garment factories normally purchase fabric from the various fabric suppliers. Prior to sourcing the textile, there are few pre-production processes handled by the production Merchandiser. Following steps are related in the pre-production stage.

- Pattern making,

- Garment sampling,

- Fabric development,

- Textiles and Accessories/trims approvals,

- Textile and Accessories/trims sourcing,

- Pre-Production meeting

Design Making - From design sketches and product details sheets, clothing patterns are created by any technical person (also defined a pattern master). Their required a format for various body parts to cut fabric to make any type of clothing. These formats are defined as a pattern. The first motif of design was created during the creation of the prototype. As the good is improved the sample is improved and the motifs are graded while creating the range set sample. Finally, prepared motifs are approved after Pre-Production garment approval.

Garment Sampling - Factories develop garments some-plus and get sample approval from their consumers. Industries are not allowed to start bulk process without garment approval. Factories required developing various types of samples at various levels of garment development.

Fabric Development - Finished woven fabrics as per the requirements of the buyer (garment manufacturer). The industry only needs to look for the fabric(s) needed for style or design.

Selection of Textile - There are thousands of textile designs and textile quality. Fabric sorting is depend on the required fabric performance such as fabric color, fiber content, tensile strength, hand feel, physical and chemical features. If the needed textile is already available in the market place, buy those textiles from the factory stock. 
Fabric development - The garment manufacturer gives the textile quality requirements to the textile supplier to upgrade a new sample design. In the fabric up-gradation step, fabric prices are discussed with fabric sellers. Laboratory dip and desk looms are up-gradated at this stage before bulk textile order. Earlier to bulk sourcing, the garment is analyzed to see if the desired value matches the improved fabric.

\section{Bulk Textile Sourcing}

Garment sourcing - At this step, there are a few calculus-as an as in the fabric of the sample. This study is done by the Pattern Yielding Department. Depend on the textile used, the total textile required for an order is created and it is encouraged from the pre-approved textile deliver. The clothes are kept in the factory or in the central store of the industry.

Textile quality inspection - Since the textiles are procured from the buyer's designated fabric delivers or from the open market place, the garment manufacturers are not ensure whether all the textiles are flawless and error free so fabric reviewing is a necessary approach. The textile may require being $100 \%$ checked or randomly checked depend on the sample quality obtained. For example, the 4 point step is utilized by industries for textile inspection and quality level grading.

Textile sort out and shade banding - It is a regular fact that when textiles are bulked, the textiles are prepared in different lots based on the power of the dyeing machine. So, there is a possibility of changing the shade of the sample of the same color. Factory-made shed bands to avoid garments shed bands.

Sourcing for the accessories and trims - All the necessary trimming and accessories are purchased similar to the encouraged fabric. Accessories and trims are started at the beginning of production in Trims requirements are calculated on the basis of trimming per sample.

Quality evaluation of trims and accessories - The quality of the trims/accessories is evaluated and finalized for production. Trims such as lace, twill tape, buttons, zippers, lace and draw cords are examined for colored losing. Destroying and damaged accessories are disparages and not used in samples.
Production Planning - All methods and approaches are pre-determined and pre-determined by the plan planner. They monitor the actual procedure activities to fulfill the order on time. The planning and developed team prepares a TNA calendar for production schedules and controls. Most T \& A makes a merchandiser.

Cutting Process - The key expensive item in making clothes is fabric. About $60-70 \%$ of clothing is spent on clothing. For the reason, clothing manufacturers use fabric wisely. A few tips on saving this fabric in the cutting room will definitely help garment manufacturers save money on sample as well.

Fabric spreading - First the textile lots are opened and spread out sheet by sheet on a cutting desk. This approach is completed by hand or using a modern spreading tool. The length of the sheet is considered by the ground on the marker range and the marker length. Multiple layers of fabric are spread over the table and all textile sheets are cut together. Usually the height of the lathe is kept as per the height of the cutting device blade.

Marker making - To create a manual marker, use a paper pattern to mark the cutter and utilize chalk to outline the designs. After evaluating the outline on the lattice, the designs are eliminated and the cutter obeys the flow chart to cut areas of the sample.

Element grading on the marker - Usually more than one sample is cut on a marker and the garment can be of various size ranges. The size is graded on the top sheet after manual grading to avoid mixing different clothing ranges during creating and sorting. For the automatic modern cutting or paper dyed markers, this marking is not needed, as all designs already bring with design and size range marking.

Set Cutting - After making the marker, the sheet is cut using a cutting devise. For one set and a tiny number of plies, scissors are generally used.

Ply enumerating - The ply enumerate is done on all the clothing elements. This method is included to keep away from color diversity of the clothing elements of the same sample. Cluster numbering is not needed in a single pc production approach. A simple hand machine is utilized to number the cut please. 
Categorizing and Bundling - The cut elements are sorted according to size range, color, dying and bundle range. It is then bundled and stored in the separate room. A pass is attached to the bundle to classify the details of the material and style.

Execute cuttings to stitching area - The cut bundle is sent to the sewing area as per the sewing division requirement and loaded on the line. Some companies like to send the whole lattice to the sewing department and the bundling of the sheet is finished on the production area.

Quality reviewing in cutting area - In the cutting area, the original quality of the cut elements such as notches, design shape, measurements of the elements and major sample defects (fabric holes, cut marks, etc.) are examined. Measurements of parts are garbed from the top, pant, middle and bottom parts and compared with actual designs and size ranges, etc.

Garment Stitching - After the cutting, sewing, and printing approach the cut ones are sent to the sewing department. A piece the operators sewn the samples and sewn the whole sample. He checks the garments mantari checker while sewing. Sewed garments should be sent to the completing or washing section if washing is needed. Garments are related in the first method of sewing.

- Part production and Marking

- Part-folding and pressing

- Stitching/assembling

- Performance reviewing

In the sewing section, workers are provided with different sewing delivers such as sewing fibers, sewing device needles, accessories, operation desire guides and additions.

Roles Preparation - The individual clothing sides are finished in the preparation section before the clothing is assembled.

Marking part - In a sample, some parts required to be identified to connect one garment element to another clearly. Marking is usually done using a chalk or modern magic pencil with the help of a format or laser beam.
Side folding and pressing - Based on the need, it may be necessary to fold part of an operator and pin it through a template. Choose, the front pocket is folded and pined before the front pocket is affixed to the chest.

Assembly section - Sample parts are organized step by step by the stuffs in order to manufacture the product. Various types of sewing machines are utilized to sew samples.

Quality evaluation on the floor - On the sewing area, the quality of sewing is reviewed by the workers. Semistitched products are usually checked to identify sewing defects. The investigator offers an oily solution to the worker responsible for creating the errors. Inline performance review, roaming review and edge-line quality examining are done on the sewing area.

Production area set-up - Sewing floor sewing device stuffs, helpers, pressmen, alternation tailors, feeders, data store, quality checkers and line supervise stuffs are among the units that require maximum manpower. In mass sample production, the yield line layout and line setting is completed before loading each new sample. Factory engineers create operation bulletins and line layouts. In the operation book, they count the manpower required and the need for the machine to create the target number of sample.

Production Reporting - Capturing production data and focusing is a key part of sample making. Information on good and performance is collected and monitored for production. Diferent types of product data are built and examined by a factory. Garment manufacturers create a data on KPIs of various manufacturing sections.

Sample Washing - Washing is completed by removing dirt, spot, and dust from the clothes. The washing method involves additional prices, so this method is done only when the consumer asks to wash their orders. Rather than cleaning samples, washing is also finished to wash numerous types of finished garments.

Garment Finishing - All clothing data are done before sending to buyers. Even a sewing shop finishes making shirts and pants. So what works are usually finished at the stage of completion of samples? The following is a short list of finishing procedures. 
Thread trimming - Garments have unrefined threads left by the sewing operator during sewing but the fibres are cut at this step. Uncut fiber can be trimmed by traditional trimmer or a cotton trimming device.

Initial sample checking - This checkpoint was set up before the dresses were ironed. Initial checking involves visual review and measurement. Finishing reviewers inspect for loose and unnecessary threads, ply number stickers, garment making, garment labeling, and manufacturer and after washing measurements. Checkers also review for sales sewing defects, clothing fabric defects and another type of defects that need to be corrected. Thus, at this step the checkers separate the defective samples and the defective samples into the repair area. All sewing errors sample are sent to a repair section. Defective samples such as stains, dirt and severe stains are given to spot removers. Few tasks such as fiber trimming and losing stickers are finished by the final checker.

Garment pressing - Sample pieces are pined by iron. Steam iron is commonly utilized for processing cotton products. In this stage, creases, folding, and creases are removed on unfinished garments and give a new look to garment products. Different types of pressing device are available by pressing garments. Dipping-ding on the sample and production range, accurate press tools is used.

Final sample checking - Stressed clothing is reexamined for determination and visual inspection. Variety of shades, exact labels of size/ages and fiber content labels are checked at this step. Any error clothing identified at this area is set for re-repair.

\section{Sample folding and final packing}

Folding - The finished samples are folded to a certain extent. Folding can also be done using the template. Different type's tags and any other type of tags are affixed to the sample after folding. The type of clothing folding varies based on the article and the needs of the buyers. Sometimes the full sample is packing in a hanger without any folds.

Packing - The folded sample is packed in a bag to retain it good until it reaches the market place. A variety of packaging trims are used to keep the sample

UniversePG I www.universepg.com in the specific size. Some goods are packed directly into paperboard box without being packed in poly bags.

Carton packing - The finished samples are boxed in large cartons for transportation.

Internal Audit - Packed samples are then reviewed for quality of outgoing finished samples. This step is followed to monitor the internal quality and to sure that no error clothing is filled in the boxes.

Finished and finally ready sample - Finally, the samples are set for shipment and finally ready for the end customers.

\section{RESULTS AND DISCUSSION:}

\section{Heading of pricing}

Total Order Quantity: 23920 PCS

Total Fabric Consumption Calculation: 14 YDS / DZN.

Total Fabric Costing Calculation: \$ 46,380.88

Total Accessories Costing: $\$ 8030.28$

CM including Washing Price Calculation: \$38.37/DZN. FOB Price: $\$ 6.20$ unit price /set.

Due to the above consumption and pricing, total order quantity 23920 pcs. 5 pocket ladies denim pants from buyer. The consumption of fabric was done by computer based design and computer aided manufacturing. The consumption of textiles actually done by right method and reduce wastage of textile in this research work. In the competitive market, fabric price reasonable with right quality according to the buyers requirement. As a production merchandiser follow up the total order in production stage like cutting, sewing, finishing and delivered the total garments goods after inspection in the buyers lead time.

\section{CONCLUSION:}

In this research work, 5 pocket ladies denim pants was studied in woven garments industry. First of all, Received order from export buyer then submitted the various sample for the motive of buyers approval. Buyers confirmed the order according to final consumption and costing from manufacturer in woven garments industry. Then production merchandiser started the whole work of buyers order for the motive of executing the buyers order in lead time. In the export order lead time is the fact for garments industry. 
Garments goods had to delivered require products on time according to the lead period. That's why as a production merchandiser, had to follow up each and every step to deliver products to maintain the quality of fabrics, accessories in the department of cutting, sewing and finishing.

\section{ACKNOWLEDGEMENT:}

The authors gratefully acknowledge the Department of Textile Engineering, Sonargaon University for technical support of this work.

\section{CONFLICTS OF INTEREST:}

The authors declared there is no conflict of interest.

\section{REFERENCES:}

1) Choudhary, A. S. (2015). Cost Analysis in Garment Industry. International J. of Recent Adv. in Multidisciplinary Res., 2, 0702-0704.

2) Camargo, M., Rabenasolo, B., Jolly-Desodt, A.M., and Castelin, J.-M. (2003). Application of the Parametric Cost Estimation in the Textile Supply Chain. J. of Textile and Apparel, Technology and Management, 3, 1-11. http://citeseerx.ist.psu.edu/viewdoc/summary?doi= 10.1.1.120.6329

3) Du, W., Zuo, D., Gan, H., \& Yi, C. (2019). Comparative Study on the Effects of Laser Bleaching and Conventional Bleaching on the Physical Properties of Indigo Kapok/Cotton Denim Fabrics. Applied Sciences, 9(21), 4662.

https://doi.org/10.3390/app9214662
4) Gandh, P., Poonkuzhali, D. and Kishore Kumar, M. (2015). Effective Cost Analysis Model for Apparel Industry. International J. of Applied Engineering Research, 10, 20263-20276.

5) Karim R, Razzak A, Mahabubuzzaman AKM, and Shahid A. (2019). Comparison of the quality parameter between cotton and melange process, Aust. J. Eng. Innov. Technol., 1(6), 2130. https://doi.org/10.34104/ajeit.019.21030

6) Kumari, A., \& Khurana, K. (2016). Regenerated Cellulose-Based Denim Fabric for Tropical Regions: An Analytical Study on Making Denim Comfortable. J. of Textiles, 1-10. https://doi.org/10.1155/2016/4614168

7) Mohibullah A $\mathrm{T}$ M, Umme Magreba Takebira, Shadman Quamar Mahir. (2019). Costing Principles of a Denim Pant, J. of Textile Science and Technolog, 5, 48-60.

https://doi.org/10.4236/jtst.2019.52005

8) Rahman, M., Asif, A. K. M. A. H., Sarker, P., \& Sarker, B. (2019). Improvement of Tensile Strength of Viscose Woven Fabric by Applying Chemical Finishes. Manufac. Sci. and Technol., 6(2), 23-30. https://doi.org/10.13189/mst.2019.060201

9) Wang, L., Lu, Y., \& He, J. (2019). On the Effectiveness of Temperature-Responsive Protective Fabric Incorporated with Shape Memory Alloy (SMA) Under Radiant Heat Exposure. Clothing and Textiles Research Journal, 38(3), 212-224. https://doi.org/10.1177/0887302x19892095

Citation: Hosen F, Hossain MM, Hassan SAKMJ, Hassan M, Alam A, and Bisal K. (2020). Assessment and evaluation of the production merchandising of a denim pant, Aust. J. Eng. Innov. Technol., 2(5), 91-100. https://doi.org/10.34104/ajeit.020.0910100 @) 